\title{
Evaluating Junior Secondary Science Textbook Usage in Australian Schools
}

\author{
Christine V. McDonald
}

(C) Springer Science+Business Media Dordrecht 2015

\begin{abstract}
A large body of research has drawn attention to the importance of providing engaging learning experiences in junior secondary science classes, in an attempt to attract more students into post-compulsory science courses. The reality of time and resource constraints, and the high proportion of non-specialist science teachers teaching science, has resulted in an overreliance on more transmissive pedagogical tools, such as textbooks. This study sought to evaluate the usage of junior secondary science textbooks in Australian schools. Data were collected via surveys from 486 schools teaching junior secondary (years 7-10), representing all Australian states and territories. Results indicated that most Australian schools use a science textbook in the junior secondary years, and textbooks are used in the majority of science lessons. The most highly cited reason influencing choice of textbook was layout/ colour/illustrations, and electronic technologies were found to be the dominant curricula material utilised, in addition to textbooks, in junior secondary science classes. Interestingly, the majority of respondents expressed high levels of satisfaction with their textbooks, although many were keen to stress the subsidiary role of textbooks in the classroom, emphasising the textbook was 'one' component of their teaching repertoire. Importantly, respondents were also keen to stress the benefits of textbooks in supporting substitute teachers, beginning teachers, and non-specialist science teachers; in addition to facilitating continuity of programming and staff support in schools with high staff turnover. Implications from this study highlight the need for high quality textbooks to support teaching and learning in Australian junior secondary science classes.
\end{abstract}

Keywords Science textbooks · Junior secondary science $\cdot$ Curricula materials $\cdot$ Scientific literacy

\section{Introduction}

An enduring problem in science education both within Australia and most developed countries is the decreasing proportion of students entering post-compulsory science courses in secondary education (Ainley and Gebhardt 2013; Ainley et al. 2008; Dekkers and de Laeter 2001; Goodrum et al. 2012). The significance of this problem lies in the flow-on effect generated

C. V. McDonald ( $\square)$

School of Education and Professional Studies, Griffith University, 176 Messines Ridge Road, Mt Gravatt, QLD 4122, Australia

e-mail: c.mcdonald@griffith.edu.au 
whereby a lower proportion of students are electing to study science at the tertiary level, ultimately resulting in fewer science professionals in the workforce (Office of the Chief Scientist 2012). Importantly, these trends need to be interpreted within the context of increasing participation in post-compulsory (typically years 11 and 12) education since the early 1980s (Ainley et al. 2008), with retention rates in Australian schools growing from approximately $35 \%$ in 1982 to a fairly constant $75 \%$ in 2009 (Lyons and Quinn 2010). Nevertheless, the most recent Australian state and territory data analysed by Kenny et al. (2014) indicates that the declining trend in post-compulsory science enrolments over the past two decades is continuing, albeit at a slightly lower rate.

A recent large-scale, national study conducted by Lyons and Quinn (2010) sought to investigate students' decisions regarding the selection of science subjects in year 11. The researchers reported that declines in post-compulsory science enrolments were likely to be caused by a number of factors related to the broader range of subject choices available to students. A central factor appeared to be the wide range of options available for tertiary study, thereby creating a competitive environment for individual subject choice. Other factors included considerations related to the perceived difficulty of some senior science subjects relative to their utility value and problems of engaging students in science (Lyons and Quinn 2010).

Other reasons proposed for the declining enrolments in post-compulsory science courses focus on students showing a declining interest in science (Goodrum et al. 2001, 2012; Millar and Osborne 1998; Speering and Rennie 1996). Some studies have shown that students feel isolated from science when the focus is on preparing science specialist students for tertiary science courses, instead of developing the scientific literacy of all science students (Fensham 1997). As such, many students feel school science is unrelated to their daily lives (Danaia et al. 2013; Tytler 2007). Other studies have highlighted a marked deterioration in students' enjoyment of science in the shift from primary to secondary school (Bennett and Hogarth 2009; Goodrum et al. 2001), with factors such as a change in the nature of teacher-student interrelationships, inflexible curriculum structures, and science programs dominated by transmissive pedagogies cited as possible influences (Speering and Rennie 1996). Dekkers and de Laeter (2001) state that secondary schools do not recognise and develop the knowledge and skills students bring forward from primary school and stress that the nature of compulsory secondary science education (typically encompassing years 7-10) is unsatisfactory and lacks a clear purpose.

The following review will highlight the role of the junior secondary years of schooling in influencing students' decisions to continue studying science in the post-compulsory years of schooling. The review will also consider current practice in the majority of science classrooms, whereby a reliance on pedagogical tools such as textbooks, has been shown to be commonplace. As such, the focus of this study is to evaluate current textbook usage in Australian junior secondary science classes.

\section{Junior Secondary Science}

A focus on the compulsory secondary school years (years 7-10), referred to as 'junior secondary' in this paper, has received increased attention in recent years. Recent research suggests student's experiences in the junior secondary years are pivotal in influencing their decisions to continue studying science in years 11 and 12. For example, Lyons and Quinn (2010) found that approximately $80 \%$ of year 10 students believed their decision to study science was chiefly affected by their most recent experiences in years 9 and 10. Similarly, Goodrum et al. (2012) reported that more than $50 \%$ of science students surveyed stated their 
interest in science developed in the junior secondary years. Other researchers have highlighted that it is during the junior secondary years that students' attitudes towards studying science and subsequent career decisions and future identities are established (Speering and Rennie 1996; Tytler et al. 2008; Tytler and Osborne 2012).

Students in the junior secondary phase of schooling are typically aged between 12 and 15 years, and as Dekkers and de Laeter (2001) highlight, this period of physical development can result in a variety of distracting influences for students. Thus, it is crucial to provide engaging, relevant and meaningful experiences in school science for these learners. Unfortunately, previous research indicates that the pedagogical practices employed in many Australian junior secondary science classes tend to be dominated by traditional 'chalk-and-talk' teacher exposition, 'recipe-style' practical activities, and copying notes from the board or textbook (Goodrum et al. 2001; Tytler 2007). More recently, teachers and students cited practical activities, real-world examples, and student-guided research as their preferred pedagogical activities, but time and resource constraints, and the inadequate qualifications of many science teachers, hampered teachers' abilities to implement more stimulating pedagogical practices (Office of the Chief Scientist 2012).

These restrictions highlight another important aspect in the junior secondary years - the central role of the teacher. In a recently commissioned survey of secondary and tertiary students, the Office of the Chief Scientist (2012) found that students cited teachers as the primary influence in their interest in, and positive attitude towards, science. A recent retrospective study conducted by Venville et al. (2013) highlighted the significant role of the teacher as influencing scientists' decisions to study science. Importantly, quality teaching in secondary science classrooms is reliant on the engagement and retention of qualified science teachers, with problems in recruiting science teachers reported in Australia for over a decade (MCEECDYA 2004). In addition to the problems in recruiting suitable numbers of physics and chemistry teachers in the senior secondary years, a significant issue for junior secondary science is the level of qualification of teachers, with research indicating less than $50 \%$ of teachers who teach general science in years 7-10 have completed two or more years of tertiary science education (McKenzie et al. 2008). Clearly, this has important implications for students, as research continues to show the persuasive influence of junior secondary science teachers on student attitudes (Lyons and Quinn 2010; Tytler et al. 2008).

Thus, although previous research indicates a preference for less transmissive pedagogical approaches in the science classroom by both teachers and students, the reality in many junior secondary science classrooms is a reliance on pedagogical tools such as textbooks (Goodrum et al. 2001). This situation is not confined to Australian classrooms, with findings from most countries mirroring the Australian condition. For example, Penney et al. (2003) highlight the current reliance on textbooks in science classes is unlikely to change, citing increasing class sizes, decreasing budgets, an ageing teacher population, and increasing safety concerns, as key factors in textbook dependency. Chiappetta et al. (1993) stress the important role of the textbook for newly qualified teachers and non-science specialist teachers who are more likely to rely on the textbook as the content outline for their classes. As stated earlier, over half of teachers teaching in junior secondary science classes in Australian schools are non-science specialist teachers (McKenzie et al. 2008). As such, these teachers often lack the necessary conceptual knowledge to effectively teach junior secondary science classes and may rely on the textbook to develop their own scientific knowledge, in addition to organising their teaching of scientific concepts. Therefore, it is vital to ensure these teachers are provided with high-quality textbooks to aid in maximising effective learning outcomes in the science classroom (Ball and Cohen 1996; Davis and Krajcik 2005). 
Textbooks play a central role in secondary science education in both developing (Irez 2009; Kahveci 2010; Ogan-Bekiroglu 2007), and developed countries (Chambliss and Calfee 1998; Chiappetta et al. 1991; Roseman et al. 2010). International studies have indicated that both classroom instruction and homework activities are heavily organised around the textbook (Chambliss and Calfee 1998; Chiappetta et al. 2006; Lumpe and Beck 1996), thus having a significant influence on the learning experiences of students (Kesidou and Roseman 2002; Penney et al. 2003). Textbooks have been shown to influence the sequence of learning, and teaching strategies employed by teachers and are often viewed as the definitive knowledge source in many classrooms (Chiappetta et al. 1991; Shamos 1995). As such, the textbook often 'becomes' the curriculum (Chiappetta and Koballa 2002).

A recent national survey conducted in the USA, supported by the National Science Foundation (NSF) with 7752 science and mathematics teachers, found that more than three quarters of middle and high school science classes use commercially published textbooks (Banilower et al. 2013). Comparable findings were found when evaluating a subset of the data from 958 middle school teachers (grades 6-8) indicating $80 \%$ of middle school science classes use commercially published textbooks (Weis 2013). Similar findings have been reported in the UK with King (2010) referring to the results of a government report (CST 2000) indicating $89 \%$ of high school teachers $(n=586)$ used science textbooks often.

A large body of research has highlighted the limitations of science textbooks. Research indicates that an overreliance on textbooks can lead to inaccurate views of the nature of science (NOS) (Chiappetta et al. 1991), with many science textbooks displaying inadequate representations of NOS (Abd-El-Khalick et al. 2008; Irez 2009). Other studies have shown that textbooks often present vast amounts of information in a superficial manner (Chiappetta et al. 1993), contain high quantities of technical terms (Groves 1995; Kesidou and Roseman 2002), an emphasis on lower cognitive-level questioning (Overman et al. 2013; Shepardson and Pizzini 1991), and often lack a cohesive and logical organisation (Alexander and Kulikowich 1994). Textbooks have been found to contain scientific misconceptions, inaccuracies and generalisations (Holliday 1991; Hubisz 2003; Roth et al. 1999), and promote gender biases (Bazler and Simonis 1991; Elgar 2004; Kahveci 2010).

Other research has shown that science textbooks can help to organise information, guide inquiry, present important scientific facts, improve problem solving skills, consolidate learning, illustrate abstractions and develop reading skills (Chiappetta et al. 2006; Lee et al. 1993; Ogan-Bekiroglu 2007; Penney et al. 2003; Schmidt et al. 1997). The development of reading skills is an important consideration in the junior secondary years as studies have found students' motivation to read deteriorates in this phase of schooling (Guthrie and Wigfield 2000), with research from the USA indicating that up to three quarters of students in some middle and high school classes are unable to read textbooks effectively (Carnine and Carnine 2004). Students are required to transition from 'learning to read' in the lower and middle primary school years, to 'reading to learn' in the upper primary and junior secondary years (Fang 2006), and this transition can be a difficult one (Johnson and Zabrucky 2011). Scholars have proposed that the shift in curriculum emphasis from chiefly narrative text to expository text is a major factor, with less familiar, subject-specific textbooks replacing the more familiar, narrative, fiction-based books (Fang 2006; Unsworth 1997). Importantly, research has suggested that prudent use of science textbooks can 
be used to improve students' reading ability (Chall and Conard 1991), particularly when textbooks are used as one tool within a wider repertoire of pedagogical activities (DiGisi and Willett 1995).

More recently, the role of the textbook as a valuable communicative tool that can be used to support the development of scientific literacy has received attention in the literature. The development of scientific literacy is the key goal of science education evidenced in reform documents internationally (American Association for the Advancement of Science [AAAS] 1993; Australian Curriculum, Assessment and Reporting Authority [ACARA] 2013) and is commonly defined as the capacity to use scientific knowledge, to identify questions and to draw evidence-based conclusions in order to understand and help make decisions about the natural world and the changes made to it through human activity (OECD 2013). In recent times, science education scholars have extended their conceptualisation of scientific literacy to focus on the 'literacy' component of the construct (Fang and Wei 2010; Hand et al. 2003; Johnson and Zabrucky 2011; Norris and Phillips 2003). These scholars claim that student conceptualisations of science are developed via oral and written communication, thus highlighting the central role of literacy skills in science education. Fang and Wei (2010) argue that limited reading skills hamper the development of deep understanding of science concepts. In addition, the manner in which textbooks are written influences the development of students' scientific literacy, as students are required to negotiate meaning from the written text, which requires an understanding of the structure and organisation of expository texts (Penney et al. 2003). Thus, science textbooks have a significant role to play in science classrooms, which has implications for their selection and use (Ford 2004).

\section{Summary and Aim of Study}

The previous review has drawn attention to the importance of providing engaging learning experiences in junior secondary science classes to tempt more students into post-compulsory science courses. Rightly or wrongly, research shows that the majority of science classes use textbooks, and in many cases, the textbook becomes the enacted curriculum. As such, the selection and use of high quality textbooks is imperative to maximise effective learning outcomes in the science classroom. Very few empirical studies on textbooks have been conducted in Australia (e.g. Ninnes 2000; Wilkinson 1999). In a related set of studies in Queensland schools, researchers sought to explore teachers' and students' perceptions of junior secondary textbook features and usage in science classrooms, with results highlighting differing perceptions regarding classroom use and purpose (Cook and Tulip 1992; Tulip and Cook 1993). Importantly, this research is now over 20 years old, and no empirical studies have been identified in the literature which have examined, on a national scale, how Australian teachers use junior secondary science textbooks. The aim of this study is to evaluate current textbook usage in junior secondary science classes in Australian schools. The research questions addressed in this study are as follows:

1. How often are textbooks used in junior secondary science classes?

2. How satisfied are teachers with their current textbook?

3. What features influence the selection of junior secondary science textbooks?

4. What curricular materials do teachers use in addition to textbooks?

5. What factors influence how textbooks are used in junior secondary science classes? 


\section{Method}

This section outlines the research methodology used in this study. The first subsection provides details of the development of the study survey, followed by a discussion of the sample and survey administration. Procedures of data analysis are then outlined, and a copy of the survey is provided in the Appendix.

\section{Survey Development}

The survey was designed to evaluate junior secondary science textbook usage in Australian schools. A review of the literature provided important information about previous survey instruments utilised to evaluate teachers' use of curriculum materials (e.g. Banilower et al. 2013). A preliminary draft of the survey was developed by the author and reviewed by two science educators. Based on feedback received, the survey was modified to remove ambiguities and improve readability and clarity. The survey was piloted with a small group of secondary science teachers $(n=5)$ in an urban area of Queensland, with further feedback received, and the survey modified again to remove ambiguities and improve readability and clarity. The final version of the survey was designed to take approximately $10-15 \mathrm{~min}$ to complete and is provided in the Appendix.

The survey consisted of a combination of closed- and open-response questions. Closedresponse questions were included in the survey as they allow respondents to answer questions in a timely fashion, are generally straightforward to answer, and allow for ease of statistical analysis. Open-response questions were included in the survey to increase the validity of the responses, as these types of questions do not force respondents to choose from a list of predetermined options (Sue and Ritter 2007). The survey questions were presented over two A4 pages and were organised into two sections. The first section requested demographic information including school name, respondent name (optional), position in school, and e-mail address (to send study results). From this information, returned surveys were able to categorised by state/territory and school type (government/catholic/independent).

The second section consisted of ten multi-part questions. Question 1 (closed-response) focused on whether the respondents' school currently utilised a science textbook or textbook series in years 7-10. If respondents answered affirmatively to this question, they were then instructed to respond to question 2. This two-part question requested the title and author of the current textbook (open-response), and information as to whether the textbook was provided in paper, electronic, or both paper and electronic format (closed-response). Responses to the second part of this question were not included in the reporting of results due to the ambiguity of the wording of this part of the question (many respondents selected all three responses instead of choosing one response). The third question (open-response) requested information about the curricular materials utilised instead of, or in addition to, the textbook at the respondents' school. Question 4 investigated the reasons why respondents chose their current textbook. Fifteen options were provided, and respondents were asked to select up to five options from the provided list (closed-response). The final option 'Other-Please state' provided respondents with the opportunity to include possible reasons that were not included in the list (open-response).

Question 5 (closed-response) asked respondents to indicate their level of satisfaction with their current textbook. Six options were provided, ranging from very satisfied to very unsatisfied, or not applicable. Question 6 (closed-response) requested information about how often respondents' schools utilised their current textbook during school science classes. Respondents were asked to respond to this question for each applicable year level (year 7, 
8, 9 and 10) and were provided with eight options, ranging from every lesson - once per term, and included an 'other' option and a 'not applicable' option. Question 7 (closed-response) asked whether the respondents' school provided a textbook hire scheme. Responses to this question were not included in the reporting of results due to differences in the interpretation of this question between states and territories. The eighth question (open-response) requested the title and author of the textbook used at the school last year (if applicable), and question 9 (closed-response) requested information about the textbook the respondents' school was planning on using next year. Three options were provided-different, same or no textbook. Respondents who selected 'different textbook' were then prompted to provide the title and author if known (open-response). The final question (open-ended) asked respondents to provide any comments they may have about the survey.

\section{Study Sample and Survey Administration}

The target population for the study sample included all schools teaching years 7-10 in Australia. As this study sought to access as many schools as possible, it was necessary to generate a sampling frame (Sue and Ritter 2007). A sampling frame is a list of the population members; therefore, in this study, the sampling frame consisted of the contact details for each school. The Australian Schools Directory www.australianschoolsdirectory.com.au was utilised to provide a list of all government, catholic and independent schools in Australia. A total of 3009 applicable schools (schools which included years 7-10) were identified from the directory, and saturation sampling (a technique where all members of the population are invited to participate in the study) was utilised.

Ethical approval to conduct the study was obtained from the relevant university ethics committee, and permission to distribute the surveys was sought from relevant educational authorities. Final versions of the survey were addressed to the Principal of each school and were accompanied by a cover letter and a reply paid envelope (except in Queensland schools where schools were e-mailed). The cover letter detailed the general nature of the study, and the aim of the survey which was to ascertain information about Australian schools' junior secondary science textbook usage. Principals were asked to pass the survey to the Head of Science to complete, subject to their approval to participate. They were informed that their participation in the study was voluntary, and they would not be contacted again with additional surveys related to the study. They were advised that there were no extraordinary risks for participating in the study, assured that individual schools would not be identified, and advised that all responses to the survey would remain confidential. Respondents were notified that their consent to participate in the study would be indicated by the return of the completed survey. They were also advised that a summary of the results of the survey would be provided to every participating school at the conclusion of the study.

In the first round of data collection (June 2012), the survey was e-mailed to all identified Queensland schools $(n=541)$. In the second round of data collection (November 2012), the survey was posted to all other identified schools in the remaining five Australian states $(n=$ $2322)$ and two Australian territories $(n=146)$. The decision to post, rather than email surveys, to the other states and territories of Australia in the second round of data collection was made due to time constraints involved in accessing email addresses for the identified schools. Nonresponding schools were sent a reminder to participate in February 2013, and all returned surveys were received by mid-2013. Summary reports outlining preliminary findings from the study for each state were e-mailed to all respondents who provided an e-mail address on their returned surveys in December 2013. 
A total of 492 surveys were returned, with four surveys discarded due to incomplete sections, resulting in a final return of 486 complete surveys. This return represented a $16 \%$ response rate across all identified secondary only, and combined primary/secondary in Australia. Importantly, results generated from this study are able to be generalised to all Australian years $7-10$ schools as the sample is representative of the general population $(95 \%$ confidence level, $\pm 4 \%$ margin of error). Table 1 provides an overview of the sample composition.

Respondents were asked to nominate their position within the school, with the large majority identifying as Heads of Science (84\%). The remaining respondents identified as science teachers $(10 \%)$ and principals/deputy principals/curriculum coordinators $(6 \%)$. Surveys were received from schools in all states and territories of Australia, with the highest percentage of surveys returned from Queensland schools (32\%), followed by NSW (24\%) and Victoria (19\%). The highest proportion of responses were obtained from government schools (48\%), followed by independent schools (30\%) and catholic schools (22\%). These figures were broadly representative of the general population with ABS (2010) data indicating the highest proportion of Australian schools (secondary only and combined primary/secondary) as government (57\%), followed by independent (26\%) and catholic (17\%).

\section{Data Analysis}

Demographic information and closed-response and open-response questions were analysed to provide the data to inform the findings of this study. Quantitative data included responses to the first section of the survey requesting demographic information and the seven closedresponse questions (or subquestions). Qualitative data included responses to the six openresponse questions (or subquestions). Quantitative data were assigned codes and entered into an SPSS file (IBM SPSS Statistics v21). Coding sheets were scrutinised for missing data values and errors, and necessary corrections made. Descriptive statistical analyses were conducted on the data set, including frequency computations and cross-tabulations.

Table 1 Overview of sample composition

\begin{tabular}{llll}
\hline & & Number & Percent of total \\
\hline Position & Head of science & 407 & 84 \\
& Teacher & 47 & 10 \\
& $\begin{array}{l}\text { Principal/deputy/ } \\
\text { curriculum }\end{array}$ & 32 & 6 \\
$\quad$ coordinator & & \\
State/territory & ACT & 7 & 1 \\
& NSW & 118 & 24 \\
& NT & 9 & 2 \\
& QLD & 152 & 32 \\
& SA & 39 & 8 \\
& TAS & 17 & 4 \\
& VIC & 92 & 19 \\
& WA & 48 & 10 \\
School type/sector & Government & 233 & 48 \\
& Catholic & 106 & 22 \\
& Independent & 143 & 30 \\
& Total & 486 & 100 \\
\hline
\end{tabular}


Qualitative data generated from respondents' answers to questions 2a, 3, 8 and 9 consisted of responses which were able to be coded into simple categories (e.g., textbook titles/authors and types of curriculum materials). A list of categories was generated for each of these questions, and corresponding codes developed. Codes and frequencies were then entered into the SPSS master file. Respondents' answers to question 4 ('other') and question 10 consisted of responses ranging from a few words to full-page responses. These responses were coded using the constant comparative method (Maykut and Morehouse 1994). In this method, predetermined categories are not used to group responses; instead, categories originate inductively from the data. The coding process for question 4 ("Why did you choose your current science textbook/textbook series for years 7, 8, 9, and 10"-Other) consisted of initially reading through the 153 responses and generating a set of 30 categories. After inspecting these preliminary categories, the researcher was able to collapse the 30 preliminary categories into five final categories which encompassed all responses. For example, preliminary categories including linked workbook, teacher resources, package inclusions, and range of activities were collapsed into a final category-Textbook inclusions/features. A similar process was carried out for question 10 ("Please add any comments you may have"). After initially reading through the 299 responses, a set of 50 preliminary categories were developed. Further analysis and collapsing of preliminary categories into similar themes resulted in nine final categories which encompassed all responses. For example, preliminary categories including eBooks, laptop school, iPads, and online resources were collapsed into a final category-Electronic technologies.

The developed categories and a subset of responses to both questions were provided to another science educator working on the study. The science educator was asked to independently code the responses, and provide feedback on the alignment of the developed categories and the data provided. The researcher and science educator met to discuss the interpretations and reach a consensus on the final developed categories and coding.

\section{Results}

This section outlines the results of the data analysis organised into five subsections. These subsections provide evidence to address the research questions guiding this study.

Frequency of Textbook Usage

The first research question sought to explore how often textbooks are used in junior secondary science classes in Australian schools. Importantly, it was first necessary to establish whether surveyed schools currently used a science textbook. A total of $87 \%$ of respondents stated their school currently used a science textbook or textbook series in years 7, 8, 9 and 10 (refer to Table 2). Slight variations existed between school types with independent schools citing a very high usage (94\%), closely followed by catholic schools (92\%). The lowest percentage usage was in government schools (82\%).

Table 2 Textbook usage

\begin{tabular}{lll}
\hline Q1. Does your school use a textbook? & Number & Percent of total \\
\hline Yes & 425 & 87 \\
No & 61 & 13 \\
Total & 486 & 100 \\
\hline
\end{tabular}


Respondents were asked about the frequency of current textbook usage during school science classes across years 7, 8, 9 and 10. Figure 1 provides information for textbook usage for each of the year levels, with results indicating a slight increase in frequency of usage from year 7 to 8 , and then a corresponding decrease in frequency of use from year 8 to 10 . When the data was collapsed to provide information about average frequency of usage across all year levels, $55 \%$ of respondents indicated their school used textbooks in every or most lessons, $27 \%$ indicated once a week, $10 \%$ once a fortnight and $8 \%$ once a month/term (refer to Table 3).

\section{Satisfaction with Textbook}

The second research question sought to evaluate satisfaction levels with current junior secondary science textbooks. Respondents were asked to rate their level of satisfaction with the current textbook used in their school in years 7, 8, 9 and 10. Results indicated that the majority of respondents from Australian schools were very satisfied/satisfied (72\%) with their current textbook/s, with $16 \%$ neutral, and $12 \%$ very unsatisfied/unsatisfied (refer to Table 4). Similar trends were found between states/territories, although some differences were evident amongst school types, with catholic (79\%) and independent (76\%) schools citing higher levels of satisfaction (very satisfied/satisfied) with their current textbook than government schools (66\%) (refer to Fig. 2).

In order to ascertain more information about textbook satisfaction, analysis was carried out on the data set to ascertain the most frequently used textbook titles. This analysis involved determining the title of the current years 7, 8, 9 and 10 science textbook in each responding school, in addition to gaining information about the textbook used in the previous year, and the textbook they were planning to use in the following year.

In total, 32 different textbooks were cited as being currently used by respondents, with some schools using a variety of different textbooks across years 7-10. The most commonly used textbook identified by respondents was Pearson Science (Pearson) (17\%), followed by ScienceWorld (Macmillan) (14\%), Science Quest (Jacaranda) (12\%), Science Focus (Pearson) (11\%) and Core Science (Jacaranda) (8\%). These five textbooks comprised over $60 \%$ of the current textbooks cited by respondents (refer to Fig. 3).

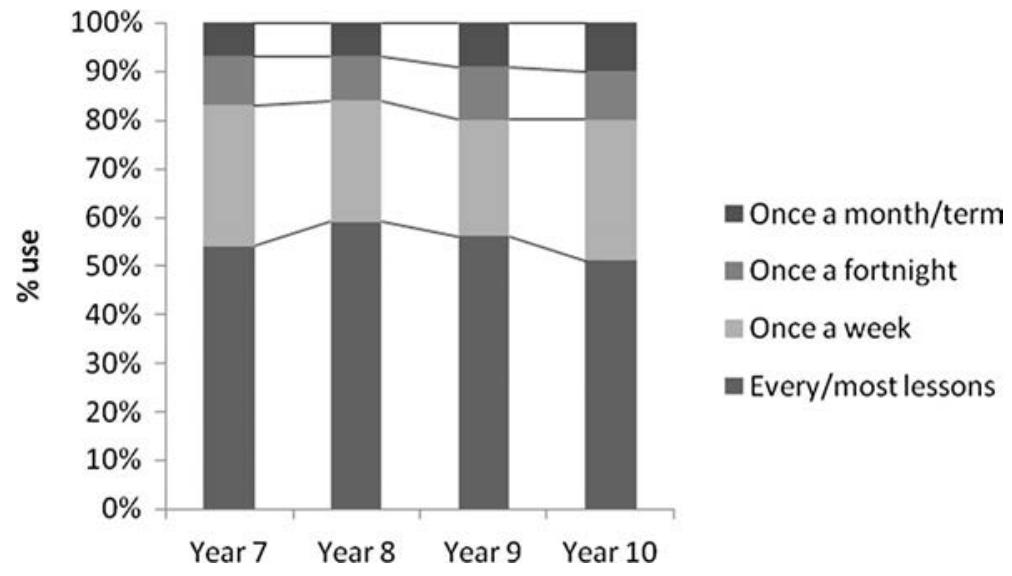

Fig. 1 Frequency of textbook usage for each year level $(N=486)$ 
Table 3 Frequency of textbook usage across years 7-10

Total exceeds $N=486$ as some respondents offered more than one response

\begin{tabular}{lll}
\hline Q6. Usage during school science classes & Number & Percent of total \\
\hline Every/most lessons & 786 & 55 \\
Once a week & 376 & 27 \\
Once a fortnight & 140 & 10 \\
Once a month/term & 115 & 8 \\
Total & 1417 & 100 \\
\hline
\end{tabular}

Over half (54\%) of respondents stated that they were currently using the same textbook/s as last year. A total of 27 different textbooks were cited as being used in the previous year, with ScienceWorld (Macmillan) (17\%) the most commonly cited textbook in the previous year, followed by Science Focus (Pearson) (13\%), Science Quest (Jacaranda) (8\%) and Core Science (Jacaranda) (8\%). These five textbooks comprised just under $50 \%$ of textbooks cited by respondents (refer to Fig. 4).

The majority of respondents $(62 \%)$ indicated that they were planning to use their current textbook next year. A total of 28 different textbooks were cited, with the most commonly cited textbook for use next year being Pearson Science (Pearson) $(24 \%)$, followed by Science Quest (Jacaranda) (15\%), ScienceWorld (Macmillan) (11\%), Science Focus (Pearson) $(10 \%)$, and Oxford Big Ideas Science (Oxford) (8\%). These five textbooks comprised almost $70 \%$ of textbooks cited by respondents (refer to Fig. 5).

This analysis highlights the dominance of a small number of junior secondary science textbooks in the Australian textbook publishing market, namely Pearson Science (Pearson), ScienceWorld (Macmillan), Science Quest (Jacaranda), and Science Focus (Pearson). Data analysis was conducted to ascertain levels of satisfaction for each of these four textbooks. Some variation was evident in the findings with the highest satisfaction levels (very satisfied/ satisfied) expressed for Pearson Science (91\%), followed by Science Quest (81\%), Science Focus $(75 \%)$ and ScienceWorld $(65 \%)$ (refer to Table 5).

\section{Textbook Features and Other Curricula Materials}

Findings presented in this subsection address the third and fourth research questions. The third research question focused on the features of junior secondary science textbooks respondents cited as influencing their schools' current choice of textbook. The most frequently selected feature for choice of textbook by respondents was layout/colour/illustrations (54\%), followed by emphasis on science content (49\%), readability (48\%), alignment with ACARA (46\%), and emphasis on science inquiry skills $(41 \%)$ (refer to Fig. 6). Similar trends were found between states/territories and school types. The 'other' option was selected by

Table 4 Satisfaction with current textbook across years $7-10$

Total differs from $N=486$ as 51 respondents offered response of 'not applicable' or 'no response'

Q5. How satisfied are you with your Number Percent of total
current textbook?

\begin{tabular}{lll}
\hline Very satisfied/satisfied & 313 & 72 \\
Neutral & 70 & 16 \\
Unsatisfied/very unsatisfied & 52 & 12 \\
Total & 435 & 100 \\
\hline
\end{tabular}




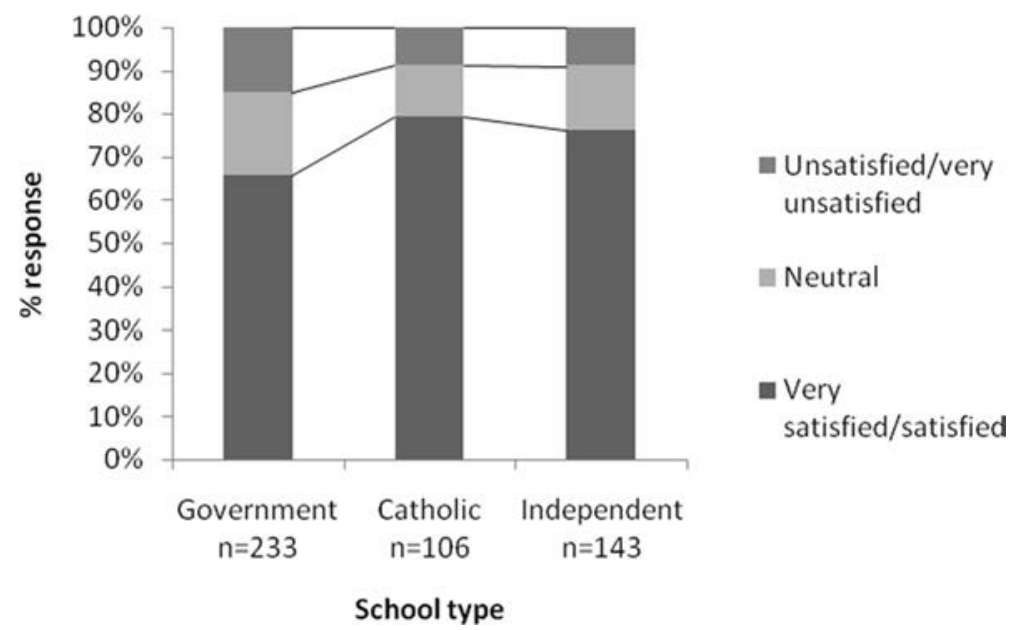

Fig. 2 Satisfaction with current textbook by school type

$29 \%$ of respondents and qualitative responses to this option were coded into five categories (refer to Fig. 7).

The highest frequency of responses to the 'other' option related to statements concerning textbook inclusions/features $(31 \%)$. Respondents referred to high-quality questions, problem-solving exercises, availability of linked resources (e.g., teacher guides, student workbooks), attention to literacy and numeracy, interesting and wide ranging activities, organised layout, good practical activities and appropriate content in this category.

Electronic technologies (25\%) were also cited by respondents and included references to iPad/laptop compatibility, availability of electronic formats (e.g., e-books), Web 2.0 content and online resources. Other respondents made reference to the fact that the textbook was previously chosen $(11 \%)$, and some made reference to the availability of the textbook for ACARA implementation (7 \%).

The fourth research question sought to ascertain the types of curriculum materials utilised in the science classroom, in addition to textbooks. A variety of open-ended

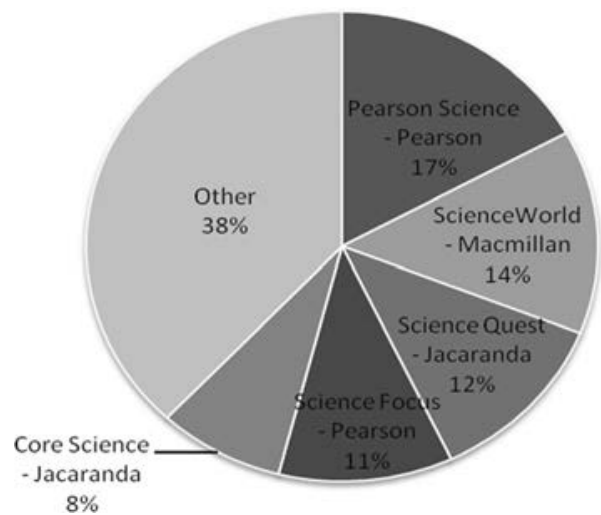

Fig. 3 Current science textbook (title/publisher) 


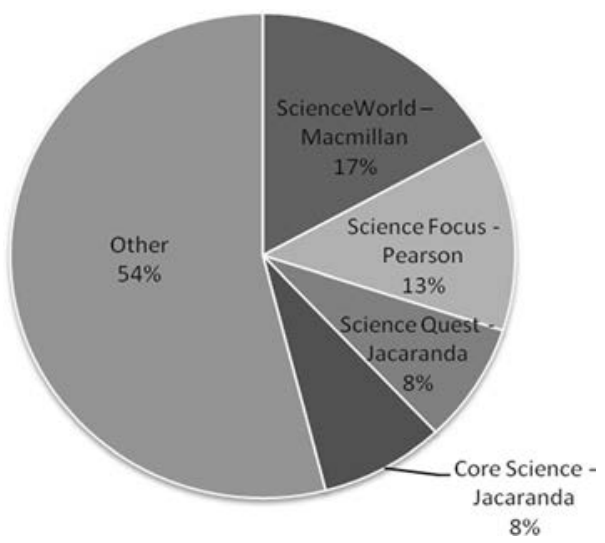

Fig. 4 Previous science textbook (title/publisher)

responses were provided by responding schools, which were coded into 12 categories (refer to Fig. 8). Over half (56\%) of respondents cited electronic technologies (websites/online activities), followed by teacher-designed resources (29\%), other textbooks/resource books $(27 \%)$ and videos/DVDs/CDroms (23\%). Reference to electronic technologies as the dominant type of curricula material utilised in addition to textbooks were evident amongst the responses received throughout all Australian states/territories, and across all school types.

Factors Influencing Textbook Use

The final research question focused on identifying factors which influenced how textbooks are used in junior secondary science classes. Respondents' open-ended comments to the final survey question (Q10. Please add any comments you may have) provided rich data to aid in addressing this research question. A total of 299 comments to this question were received, representing $62 \%$ of respondents. Data analysis resulted in the coding of all responses into nine categories (refer to Fig. 9).

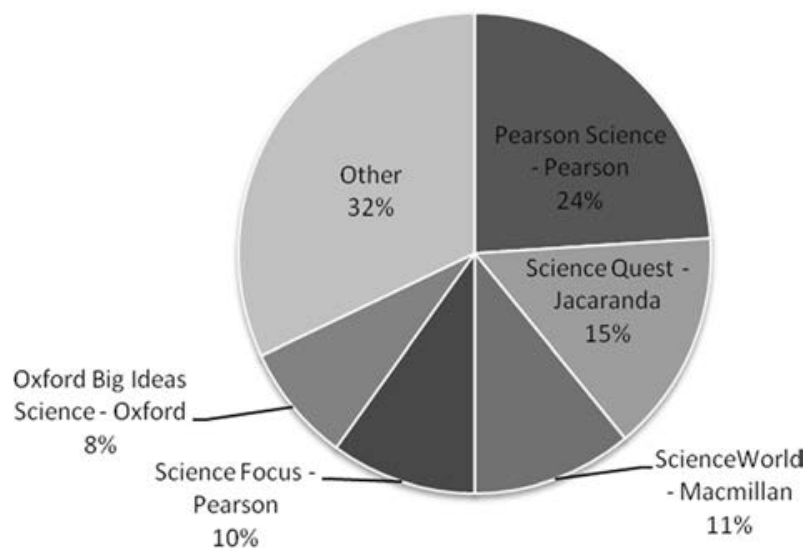

Fig. 5 Future science textbook (title/publisher) 
Table 5 Satisfaction with dominant textbooks

\begin{tabular}{|c|c|c|c|c|c|c|c|c|}
\hline \multirow[t]{2}{*}{ Satisfaction with dominant textbooks } & \multicolumn{2}{|c|}{ Pearson Science } & \multicolumn{2}{|c|}{ ScienceWorld } & \multicolumn{2}{|c|}{ Science Quest } & \multicolumn{2}{|c|}{ Science Focus } \\
\hline & $n$ & $\%$ & $n$ & $\%$ & $n$ & $\%$ & $n$ & $\%$ \\
\hline Very satisfied/satisfied & 72 & 91 & 48 & 65 & 48 & 81 & 43 & 75 \\
\hline Neutral & 5 & 6 & 14 & 19 & 6 & 10 & 12 & 21 \\
\hline Unsatisfied/very unsatisfied & 2 & 3 & 12 & 16 & 5 & 9 & 2 & 4 \\
\hline Total & 79 & 100 & 74 & 100 & 59 & 100 & 57 & 100 \\
\hline
\end{tabular}

The following subsections will discuss comments received in each category (excluding "Other") supported by representative quotes from respondents.

Alignment to ACARA The highest number of comments offered by respondents focused on alignment of textbooks with ACARA $(n=77)$. Importantly, almost half of the comments in this category were from NSW respondents commenting that they were yet to commence the Australian curriculum (due for implementation in 2014):

"We are waiting to see new texts produced to best meet ACARA" (NSW 27)

"The new textbook is for the AC" (NSW 81)

Comments in this category were not confined to NSW schools, but also received from all Australian states and territories:

"New texts will need to align to the Australian Curriculum" (QLD 67)

"Main reason for change was alignment with AC..." (VIC 2)

"Hopefully the new textbook will support us as we update/change to the new Australian Curriculum..." (WA 12)

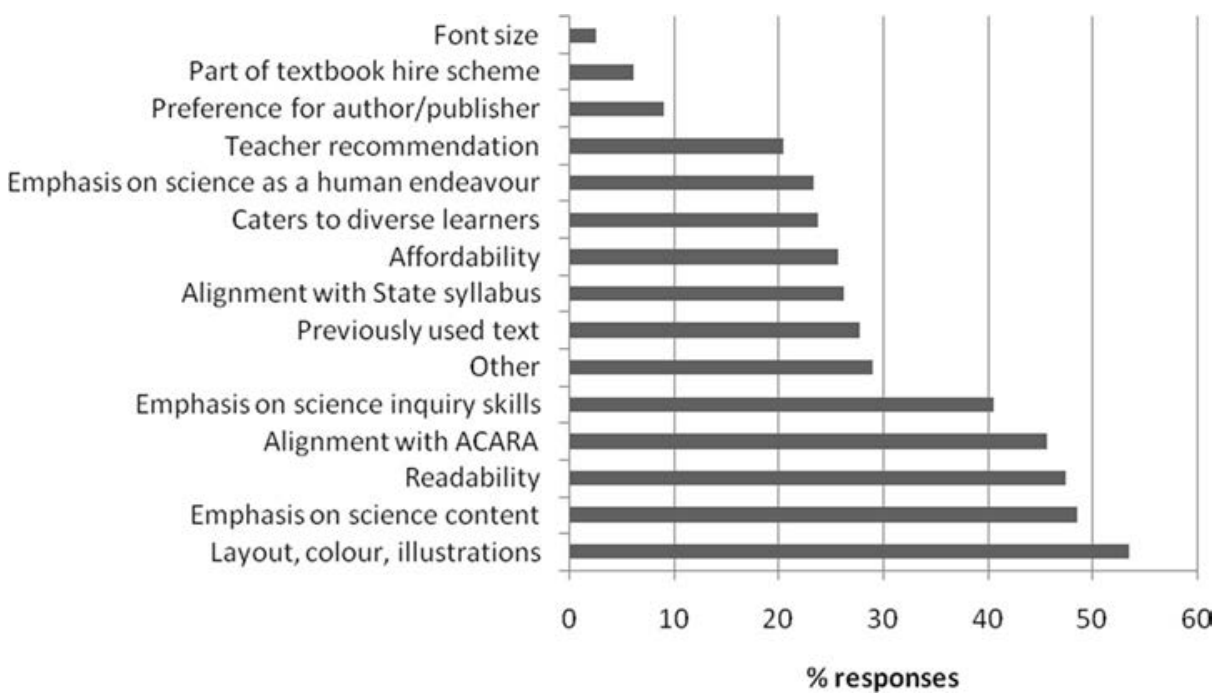

Fig. 6 Features influencing textbook selection $(n=453)$ 


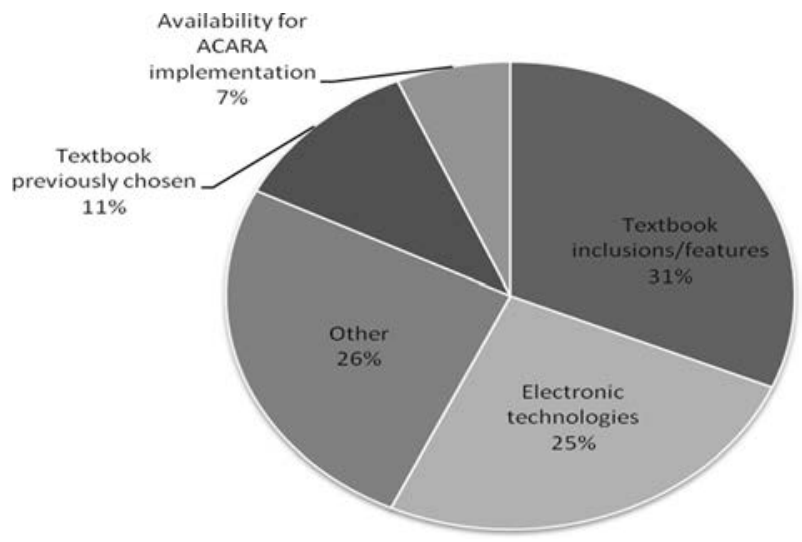

Fig. 7 Qualitative responses to 'Other' option for textbook selection $(n=132)$

Electronic Technologies The second highest number of comments offered by respondents focused on electronic technologies $(n=69)$. Many respondents commented on how their schools were transitioning towards implementation of electronic technologies in the classroom, with a number of respondents making reference to their schools' laptop programs:

"We have just begun to transition to iPads..." (NSW 42)

"Moving towards online content" (VIC 9)

"Have 1:1 digital device program so electronic text is essential" (SA 2)

Other respondents highlighted how the shift towards electronic technologies (specifically the Internet) has resulted in a reduced emphasis on textbooks:

"Each year we have become more web focused and less text focused" (NSW 51)

"With the ease, visual attentiveness, interactive and real hands-on activities (internet)

there is limited reliance on textbook materials for students..." (NT 3)

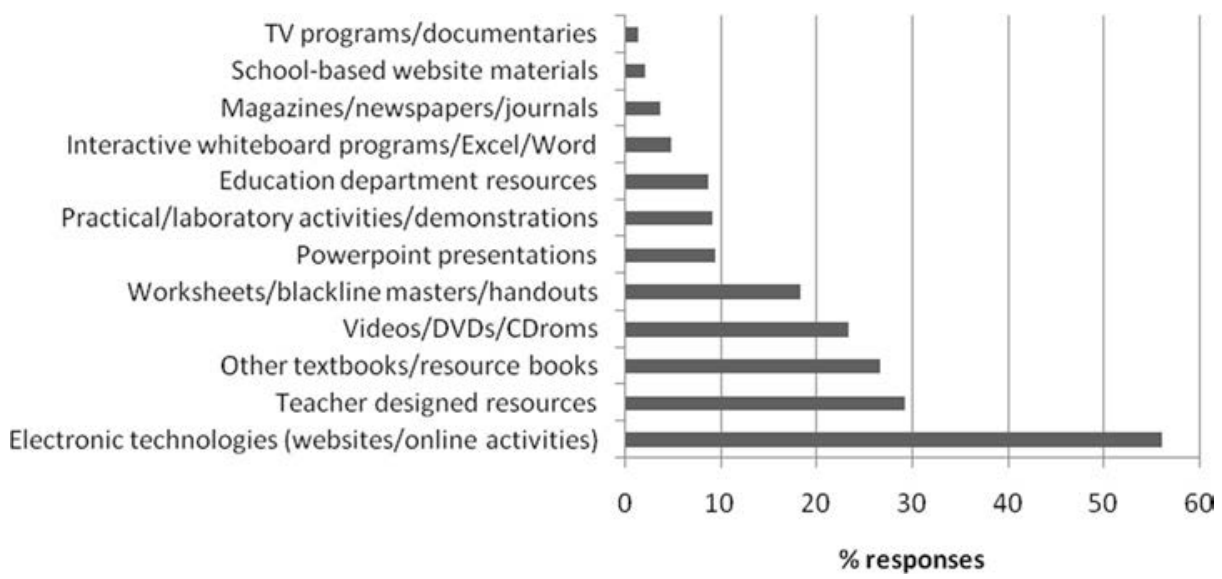

Fig. 8 Curricular materials used in addition to textbooks $(n=486)$ 


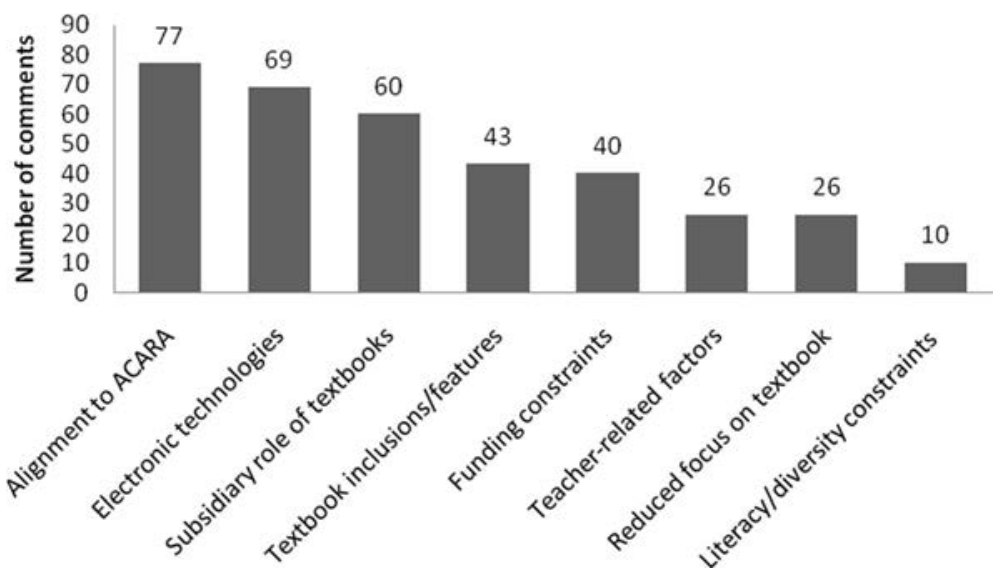

Fig. 9 Factors influencing textbook usage $\left(n=351^{1}\right)$

Many respondents drew attention to the affordances offered by electronic technologies, including access to a wide range of knowledge and resources, and the ability to cater to different teaching and learning styles:

"A wide variety of online resources assist in the presentation of key concepts from the AC" (ACT 4)

"Online resources (laptop school) are more extensive and make for more versatility to suit individual styles of various teachers (WA 1)

"We also have a one to one laptop program and feel we can utilise a whole wealth of knowledge (up to date) using the internet" (VIC 18)

"...we are endeavouring to use more ICT resources to make learning more relevant and exciting for students" (QLD 75)

Subsidiary Role of Textbooks The third highest number of comments offered by respondents drew attention to the subsidiary role of textbooks in the classroom $(n=60)$. Many respondents were keen to stress that the textbook was 'one' component or tool used within a wider range of curricula activities:

"Text usually features for 'part' of the lesson. Never the whole" (NSW 54)

"...Teachers are encouraged to use a range of resources and not be solely relying on the text” (WA 4)

"Texts are generally used as a guide to the type of topics/content to be addressed but details and approach are determined by the teacher..." (VIC 40)

“...A textbook is simply a tool to use to enhance teaching and learning” (QLD 31)

Other comments highlighted the role of the textbook as a support, or back up, for learning, with some respondents stating the text was only used for homework, or when the regular science teacher was absent:

“Textbooks provide a back up for our development of resources..." (NSW 22)

\footnotetext{
${ }^{1}$ Total differs from $n=299$ as some respondents offered more than one response, and 'Other' category $(n=45)$ not shown. This category included non-specific comments such as "Good luck with your survey", "Hope the information is helpful," etc.
} 
"We use textbooks as a resource for kids to consolidate what is taught, often as background reading" (TAS 9)

"Textbook use depends on the topic, often it is used for homework but not in class" (NSW 80)

Many respondents indicated that their schools did not rely on one particular textbook and utilised a number of different textbooks in the classroom. They commented that multiple texts were used to enable them to select the suitable components:

"We do not base our teaching programs on any particular text. We have access to five different texts and use them in lessons where they best fit" (NSW 39)

"Most of the time teachers teach from a variety of text, not limited to one. Some texts offer better explanation" (WA 11)

"I also encourage use of 'multiple' texts as I do not believe that one single source of information is a) always the best and b) is not modelling good science/inquiry/creative thinking, etc." (SA 16)

"If I could choose I would use several different textbooks so I could pick the best, most useful bits out" (TAS 5)

Textbook Inclusions/Features A high number of comments $(n=43)$ focused on textbook inclusions/features were offered by respondents. Many of these comments highlighted the importance of textbook companion resources (teacher guides, student workbooks, linked electronic resources, etc.), in particular, the provision of effective student workbooks:

"Publishers are recognising the need to supply resources with their texts..." (NSW 78)

"Teacher support materials are very important" (QLD 19)

"...Disappointed that there are not electronic resources to supplement textbook" (SA 24)

"We like ...the use of an obook (workbook) as it is becoming increasingly difficult to get kids to bring/write in a workbook" (VIC 5)

"Would have liked a better student workbook (text) or at least homework book..." (WA 13)

Other comments from respondents focused on problems with the layout/colour/illustrations of textbooks:

"Due to the nature of students in our school, the condensed, visually confusing nature of regular texts does not prove helpful" (NSW 56)

"They seem all gloss and pictures with no extensive lab exercises or in-depth studies, etc., to engage the students..." (NT 1)

"Current textbooks... have gone for colours and pictures rather than scientific information and pictures (QLD 61)

"Current texts ... a rip off due to cut and paste organisation..." (WA 3)

Many respondents also highlighted problems with the quality, type and complexity of questions and exercises contained in textbooks. These comments were particularly prevalent from Queensland respondents:

"I could really do with a textbook that focused on questions that were not regurgitating knowledge...The stuff I need is the evaluate, analyse, graph, tabulate, hypothesise... stuff” (QLD 37)

"I am hopeful that with the advent of the National Curriculum that the quality will improve, particularly the number and depth of questions..." (QLD 41) 
"The new (text) does not have the Science Inquiry Skills questions we want students to be challenged with" (QLD 53)

Other respondents expressed concerns with the ability of textbooks to support inquiry based learning:

"Textbooks need to be practical based to encourage hands on learning..." (NSW 87)

"...I have found the most successful activities with middle school are project-based/ hands on..." (NT 1)

"Textbooks are not compatible with inquiry based learning" (SA 10)

Concerns about the level of complexity of textbooks, amount of content and readability of textbooks were also expressed:

"We have some issues with the degree of complexity..." (TAS 7)

"We would like to change to a National curriculum textbook but all are too wordy and dense with content" (VIC 17)

"We are finding our textbooks as well as others viewed are very content laden - a lot jammed into each text..." (WA 6)

"...Readability (text) suits majority of students (low band school)" (VIC 8)

The final group of comments focused on how 'Science as a human endeavour' was represented in textbooks, with many respondents expressing concern with how this important component was portrayed:

“...they have, however, not done a great job with the SHE component" (QLD 32)

"Science as a human endeavour did not appear to be well covered in any textbooks we looked at" (QLD 57)

"It is evident that embedding the Nature of Science is difficult..." (SA 26)

Funding Constraints Many comments offered by respondents focused on funding constraints $(n=40)$. Some of these comments focused on the high cost of new textbooks, with many respondents stating that limited funding impacted on how frequently they replaced their textbooks. As a consequence, some respondents indicated that they were using textbooks that were several years old. These comments were particularly prevalent from Tasmanian respondents:

“Textbooks are extremely expensive..." (ACT 3)

"Most books are too expensive for a small school with a shrinking budget..." (TAS 10)

"Due to limited funding we don't regularly change textbooks" (NSW 77)

"Very difficult to change from a series once it has been purchased..." (WA 23)

"Our textbooks are several years old now" (NSW 21)

"We have a very low resource base. We generally rely on purchased texts from the past 40 years" (TAS 6)

Other comments focused on the high cost of supporting electronic technologies. Respondents expressed concern about the costs to maintain electronic upgrades, internet access fees, and digital copyright fees:

"Students will not pay for digital copyright fees" (NSW 8)

"...They keep charging us to upgrade $30 \%$ ebooks each year and make us buy new ebooks not linked to texts at full price each year-too expensive, may not continue" (NT 4) 
"I am concerned about the change from supplying digital content on CDs to internet access - need for a cost each year/maximum of four years for 'life' of book" (SA 14) "...we might be tempted into some of the more expensive digital options but publishers have tied up their electronic material with access limits for either a year or four years..." (QLD 81)

Some respondents made reference to contextual constraints, such as the affordability of textbooks for parents, particularly in low socioeconomic areas:

"Affordability to parents essentially..." (VIC 38)

"The price of textbooks is too high for public schools..." (WA 28)

"We are buying class sets... due to our students being from disadvantaged backgrounds" (VIC 3)

Other respondents emphasised the funding constraints imposed by the changing curriculum:

“...Curriculum changes often, and public school budgets cannot allow for textbook changes to keep up with curriculum demands..." (WA 28)

"Have had to allocate \$ (large amounts) to cater for ACARA expectations..." (SA 17)

Teacher-Related Factors A number of comments offered by respondents focused on teacherrelated factors $(n=26)$. Many comments in this category highlighted the benefits of using textbooks, particularly when the regular science teacher is absent, and a substitute teacher is required to teach the class:

"Textbooks used when staff away_-good relief lessons" (ACT 1)

"Texts are commonly used for casual teachers" (NSW 39)

"Teachers generally only use text to set work during their absence" (QLD 6)

Other benefits cited by respondents related to the usefulness of the textbook to support beginning teachers, and non-specialist science teachers:

"...the use of a textbook is very helpful until they establish themselves. Very difficult to help beginning teachers across broad range of science now expected for teaching." (QLD 64)

“...new staff like them as I guess they need some support in their pedagogy in the classroom" (SA 4)

"Handy for when non-science trained teachers are taking the class" (NSW 31)

Some respondents commented that due to high staff turnover, textbooks provide continuity of programming and staff support:

"Smaller schools need to have a highly structured program so that when large staff changes occur, it is easier to get continuity with the science program..." (NSW 19)

"Due to a large turnover of staff and a resultant reduction in content depth and breadth of knowledge we will be returning to a textbook system to support staff development" (QLD 54)

Although a number of benefits were cited by respondents regarding teacher-related factors, some concerns were expressed in this category. Time and workload constraints and parental pressure were cited as leading to an increased reliance on textbooks:

"Time constraints mean that most teachers like to have a textbook as a starting point..." (VIC 31) 
"Time constraints do not allow me to find many other sources of material" (QLD 48)

"Volume of use of textbooks increased due to parent request" (NSW 67)

"Parents push for the text..." (QLD 28)

Finally, some respondents indicated that their schools needed to use textbooks as teachers' science knowledge was often considered deficient, resulting in teacher requests for a textbook. Many of these comments came from Victorian respondents:

"I do worry that the knowledge of some teachers is lacking so they 'need' the textbook" (VIC 17)

“...due to teacher need/desire..." (VIC 45)

"Staff could not cope without a text... so we have gone back to it" (VIC 6)

Reduced Focus on Textbook A reduced focus on textbooks was the spotlight of a number of comments $(n=26)$ offered by respondents. Many comments in this category made reference to the decreasing reliance on textbooks in their school:

"We are finding that we use the text less and less and will probably not issue them in 9/

10 next year" (NSW 43)

"We ... are moving away from textbooks" (SA 10)

"...We are using texts far less than in previous years" (QLD 66)

Other respondents highlighted that textbook use in their school varied, depending on individual teacher preference:

"Some teachers use textbook almost exclusively, some not at all, some use simply as an occasional resource" (NSW 51)

"...Teachers have got used to not using a textbook. In the past their use has been variable - some never used them in class except for planning purposes, and some used them all the time" (QLD 13)

A number of comments focused on the negative implications of using textbooks, with some respondents indicating textbooks confine them into somebody else's interpretation of the curriculum:

"Texts promote 'lazy' teaching..." (NSW 14)

"Using a textbook means that we are following somebody else's opinion and interpretation of the syllabus" (QLD 20)

"We believe a textbook locks us into someone else's curriculum..." (NSW 79)

Literacy/Diversity Constraints The final category comprised a small number of comments $(n=10)$ focused on literacy/diversity constraints, with the majority of respondents' comments in this category highlighting how textbooks failed to cater to their students' needs:

"For the past three years we have programmed lessons in context to our learners. Textbooks do not cater for our diverse needs" (NSW 70)

“...ESL high school—needs highly scaffolded learning materials" (QLD 26)

"The book that we are using (text) is too hard for ESL students" (VIC 11)

"The new books test the literacy of our students. The ESL and IEC students find the books very difficult to read..." (WA 16) 


\section{Discussion}

The aim of this study was to evaluate current textbook usage in junior secondary science classes in Australian schools. Previous research has highlighted the importance of providing engaging learning experiences in junior secondary science classes, although time and resource constraints, and the high proportion of non-specialist science teachers teaching science, has resulted in an overreliance on science textbooks in the classroom. Thus, the selection and use of high quality textbooks is imperative to maximise effective learning outcomes in the science classroom. The results of this study indicate a large majority (87\%) of Australian schools currently use a science textbook in the junior secondary years. This finding aligns with research conducted in other developed countries (CST 2000; Banilower et al. 2013; Weiss 2013), highlighting the pervasive use of textbooks internationally. Frequency of textbook use in this study across years 7-10 was found to be comparable, with over half of schools surveyed indicating textbooks were used in the majority of science lessons (RQ1).

Findings indicated high levels of satisfaction with junior secondary science textbooks with the majority of respondents from Australian schools expressing they were very satisfied/ satisfied (72\%) with their current textbook/s (RQ2). Although this was a somewhat unexpected finding, as many previous studies have highlighted issues with the quality of science textbooks (Chiappetta et al. 1993; Kesidou and Roseman 2002), this result aligns with recent findings from the USA, where the majority of teachers surveyed in the recent NSF survey (Banilower et al. 2013) considered their textbooks to be of relatively high quality, with results showing that in approximately three quarters of classes the materials were rated good, very good or excellent. Slight variations in satisfaction levels were evident in this study amongst school types, with government schools citing slightly lower satisfaction levels than catholic and independent schools. In addition, some variation was evident in the satisfaction levels of the four dominant Australian junior secondary science textbooks identified, with satisfaction levels ranging from $65 \%$ (ScienceWorld) to $91 \%$ (Pearson Science) for the very satisfied/ satisfied criterion.

A number of features were shown to influence the selection of junior secondary science textbooks in this study (RQ3). These features differed from those identified in the study of Cook and Tulip (1992), where generic preferences for textbook features promoting student cognition, and positive attitudes and motivation were commonly cited. The most frequently chosen feature by respondents in this study was layout/colour/illustrations, closely followed by emphasis on science content, readability, alignment with ACARA and emphasis on science inquiry skills. Many respondents highlighted the limitations of poor layout/colour/illustrations and expressed concern about the overuse of colours and images in textbooks, at the expense of important conceptual information. Others referred to problems with the organisation of materials, often resulting in condensed, piecemeal treatment of scientific concepts. The importance of an organised layout to minimise confusion for students was also emphasised. These findings align with previous research indicating the dominance of illustrations in science textbooks, with some studies reporting up to $50 \%$ of page space being utilised for illustrations, in addition to a lack of coherence between the illustration and the related content (Mayer et al. 1993; cited in Lee 2010). Other studies have shown an concerning trend towards the increased use of photographs and other 'decorative' graphics, instead of schematic or explanatory illustrations in an attempt to make texts more familiar and less demanding to students (Lee 2010; Slough et al. 2010).

Issues with readability were also identified in this study. Many respondents highlighted problems with the complexity of textbooks and expressed concerns with the density of 
textbook content. Similar findings have been reported in previous studies (e.g. Carnine and Carnine 2004; Unsworth 1997) and draw attention to the importance of ensuring junior secondary students are provided with explicit instruction in negotiating expository texts as a central component of the development of their scientific literacy (Fang 2006). As stated earlier, student conceptualisations of science are developed via oral and written communication, thus highlighting the central role of literacy skills in science education. This presents a considerable challenge for Australian secondary students as the latest findings from the Programme for International Student Assessment (PISA) in 2012 show that Australian secondary students' average reading literacy performance has declined significantly over the past 12 years (Thomson et al. 2013).

Alignment with ACARA was also identified as an important feature for textbook selection in this study. Indeed, references to this feature in the qualitative data analysis resulted in the highest number of comments offered by respondents, with many respondents expressing they were waiting to evaluate textbooks to ascertain their fit with the Australian Curriculum (particularly NSW respondents who had yet to commence the Australian Curriculum at the time of data collection), or expressed that alignment with the Australian Curriculum was an important consideration in their decision making regarding future textbooks. Another important feature identified as influencing textbook selection focused on 'emphasis on science inquiry skills.' This core strand of the Australian Curriculum is concerned with "....identifying and posing questions; planning, conducting and reflecting on investigations; processing, analysing and interpreting evidence; and communicating findings" (ACARA 2013, p. 6), and is closely aligned with inquiry-based teaching approaches.

Interestingly, teaching approaches in science classrooms are often labelled as 'textbook-based' (teaching predominantly follows textbook content) or 'inquiry-based' (teaching predominantly involves engaging students in hands-on investigations) (Kahveci 2010). Norris and Phillips (2003) state that these teaching approaches are often represented as oppositional in nature, particularly in classrooms where inquiry-based instruction dominates. This can be problematic as many conceptual areas of science, such as astronomy, require scientific explanations that cannot easily be developed via handson experiences (Ford 2004). In these cases, textbooks have been found to aid in facilitating the development of scientific understandings. Importantly, a recent study conducted by Dunne et al. (2013) analysed several Irish primary school science textbooks and found that textbooks can support the implementation of inquiry-based teaching approaches by providing teachers with supporting content knowledge and various learner-centred pedagogical practices. These are important considerations as some respondents in the present study expressed concern with the ability of textbooks to support inquiry based learning.

Other textbook features cited by respondents focused on the importance of providing textbook companion resources such as teacher guides, student workbooks, and linked electronic resources, and the inclusion of high-quality questions and exercises, with many respondents expressing concern about the quality, type and complexity of questions and exercises contained in textbooks. These findings align with previous research which indicates the dominance of lower cognitive-level questioning in many textbooks (Overman et al. 2013; Shepardson and Pizzini 1991).

Results from this study indicate that Australian teachers utilise a wide range of curriculum materials in the science classroom, in addition to textbooks (RQ4). 
Importantly, a high number of respondents drew attention to the subsidiary role of textbooks in the classroom and were keen to stress that the textbook was 'one' component of their teaching repertoire, used within a wider range of curricula activities. Many highlighted the role of the textbook as a support for learning, indicating that their schools did not rely on one particular textbook, instead utilising multiple texts to suit their individual approaches to teaching. These findings are supported by recent research in the USA which found that although the majority of science classes use textbooks, approximately half of middle school science classes spend less than $50 \%$ of their instructional time utilising these curricula resources. In addition, three quarters of teachers supplemented the materials (with problems, investigations, and readings), and half selected components from the textbook they considered important, and ignored the other components (Weis 2013).

Electronic technologies were found to be the dominant curriculum material utilised in the classroom, in addition to textbooks, by over half of the respondents in this study. Other highly cited curriculum materials included teacher-designed resources, other textbooks/resource books, and videos/DVDs/CDroms. The significant role of electronic technologies in the science classroom was evident from respondents' comments (RQ5), with many schools transitioning towards the implementation of electronic technologies in the classroom, resulting in a reduced emphasis on traditional paper-based textbooks. Respondents were keen to emphasise the numerous advantages of utilising these technologies, including the ability to access a wide range of knowledge and resources, and cater to different teaching and learning styles. Interestingly, the dominance of electronic technologies in the classroom was not supported by recent findings emerging from research conducted in the USA, with Weis (2013) reporting that fewer than one third of middle school science classes utilised electronic technologies at least once a week, even though the large majority of these classes had access to these technologies. Importantly, the utilisation of electronic technologies such as ebooks is a relatively recent phenomenon, with little research conducted to ascertain the relative affordance or constraints of utilising these tools. Khine (2013) reports mixed results from the handful of studies conducted to assess the effectiveness of utilising electronic resources, over traditional, paper-based textbooks. As such, this is an important area of future research.

Other factors which were found to influence how textbooks are used in junior secondary science classes related to funding constraints, teacher-related factors and literacy/diversity needs. Results indicated that concerns about the high cost of new textbooks and limited funding for replacing textbooks were common, in addition to concerns expressed about the high cost of supporting electronic technologies. Contextual constraints, such as the affordability of textbooks for parents and curriculum changes were also cited. These findings are supported by recent data from PISA 2012 (Thomson et al. 2013) indicating that, although, on average, Australian schools had access to high quality educational resources, compared with other OECD countries, up to one third of principals in some states and territories reported a shortage or inadequacy of instructional materials (textbooks). In addition, findings from the latest Trends in International Mathematics and Science Study (TIMSS) 2011 survey indicated approximately half of Australian principals reported resource shortages in year 8 science classes (Thomson et al. 2012). Similar concerns have been expressed in the USA, with inadequate funding for purchasing equipment and supplies (including 
textbooks) cited as the most serious problem for science instruction across the elementary, middle and high school years (Banilower et al. 2013).

Teacher-related factors were found to influence how textbooks were used in this study. Some concerns were expressed about an increased reliance on textbooks due to time and workload constraints, parental pressure and teacher requests. Rennie et al. (2001) reported similar findings with one in five teachers citing a lack of time to prepare, reflect and collaborate as limiting the quality of teaching and learning in science classes. More recently, Goodrum et al. (2012) reported constraints related to time as the central factor limiting the teaching science in Australian years 11 and 12 science classes, and in the US context, Weis (2013) also cited time constraints as a factor influencing effective instruction in middle school science classes, with $63 \%$ of teachers stressing the importance of planning time for effective science instruction. On the other hand, many respondents drew attention to the usefulness of the textbook to support substitute teachers, beginning teachers, and non-specialist science teachers, in addition to facilitating continuity of programming and staff support in schools with high staff turnover. These findings are supported by previous research (Ball and Feiman-Nemser 1988; Reddy 2005; Stern and Roseman 2004) which suggests that teachers have an increased reliance on curriculum materials such as textbooks when they are inexperienced or teaching outside of their subject area. Importantly, Stern and Roseman (2004) point out that many teachers in the middle school/junior secondary years to not hold a university major in science, thus limiting their ability to plan and teach science classes effectively. A lack of adequate tertiary preparation for teaching into the junior secondary years was also reported in the Australian context by McKenzie et al. (2008). These finding highlight the importance of providing highquality science textbooks to support these teachers and to facilitate ongoing stability of programming for schools experiencing high staff turnover rates.

\section{Implications and Future Research}

This study has made an original contribution to the field in that it is the first empirical study identified in the literature which has examined, on a national scale, junior secondary science textbook usage. Implications from this study highlight the need for high quality junior science textbooks, particularly to support substitute teachers, beginning teachers, and non-specialist science teachers in Australian schools. Further research into the role of electronic technologies in the science classroom is needed to ascertain the impact of these dominant curricula materials on learning outcomes for students. Importantly, this research needs to incorporate the perspectives of not only science teachers, but also science teacher educators, science education researchers, and textbook developers/writers, to enable a holistic overview of the role of these technologies to be undertaken. Importantly, recent research has drawn attention to the critical role of textbooks in supporting the development of the 'literacy' component of scientific literacy, in addition to the supporting role these curriculum materials can provide in inquiry-based learning environments. This is a crucial area of future research as the development of students' scientific literacy is considered to be the key goal of science education in Australian schools (ACARA 2013). Acknowledging that textbooks may, in fact, play a role in supporting this development continues to be a contentious assertion. 


\section{Appendix}

\section{AUSTRALIAN SCHOOL SCIENCE TEXTBOOK SURVEY}

School name:

Your name:

(Optional)

Position:

Email address:

(For study results)

1. Does your school currently use a science textbook/textbook series in Years $7,8,9$, and 10 ?

$$
\text { CYes (go to Question 2) C C No (go to Question 3) }
$$

2. (a) What is the title and author of the science textbook/textbook series?

(b) Is the science textbook/textbook series provided in paper format (traditional book) or electronic format (e.g., CD/DVD, online, laptop program)?
C Paper format
C Electronic format
C Both paper and electronic format

3. What curricular materials do you use instead of, or in addition to, a science textbook?

4. Why did you choose your current science textbook/textbook series for Years 7, 8, 9, and 10? Please select up to five (5) responses from the following options:

$\Gamma$ Affordability

$\Gamma$ Part of textbook hire scheme

$\lceil$ Previously used text

$\Gamma$ Teacher recommendation

$\Gamma$ Preference for author/publisher

$\Gamma$ Emphasis on science content

$\lceil$ Emphasis on science inquiry skills

$\lceil$ Emphasis on science as a human endeavour

$\Gamma$ Layout, colour, illustrations

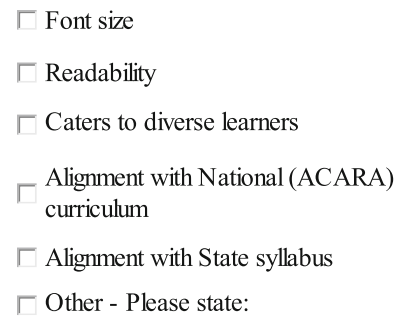

PLEASE TURN OVER $\rightarrow$ 
5. How satisfied are you with your current science textbook/textbook series in Years 7, 8, 9, and 10 ?
C Very satisfied
CUnsatisfied
CSatisfied
C Very unsatisfied
C Neutral
C Not applicable

6. On average, how often is your current science textbook/textbook series used during school science classes in Years 7, 8, 9, and 10?
Year 7
Year 8
Year 9
Year 10

C Every lesson

C Every lesson

C Every lesson

C Every lesson

C Most lessons

C. Most lessons

C Most lessons

C Most lessons

C. Once a week

E Once a week

C. Once a week

COnce a week

C Once a fortnight

C Once a fortnight

C Once a fortnight

COnce a fortnight

C Once a month

COnce a month

C Once a month

E Once a month

C Once per term

C Once per term

C Once per term

C Once per term

COther

COther

COther

C Other

C Not applicable

[ Not applicable

C Not applicable

C Not applicable

7. Does your school provide a textbook hire scheme to students in Years $7,8,9$, and 10 ?
CYes
CNo

8. What was the title and author of the science textbook/textbook series you used last year in Years 7, 8, 9, and 10 (if applicable)?

9. What science textbook/textbook series are you planning on using next year in Years 7 , 8,9 , and 10 ?

C Different textbook/textbook series than 2012 - Please state title and author if known -

C Same textbook/textbook series as 2012

C No textbook/textbook series

10. Please add any comments you may have:

Thank you for taking the time to complete this survey! 


\section{References}

Abd-El-Khalick, F., Waters, M., \& Le, A.-P. (2008). Representations of nature of science in high school chemistry textbooks over the past four decades. Journal of Research in Science Teaching, 45(7), 835-855.

Ainley, J., \& Gebhardt, E. (2013). Measure for measure: a review of outcomes of school education in Australia. Camberwell: Australian Council for Educational Research.

Ainley, J., Kos, J., \& Nicholas, M. (2008). Participation in science, mathematics and technology in Australian education. Camberwell: Australian Council for Educational Research Ltd.

Alexander, P. A., \& Kulikowich, J. M. (1994). Learning from physics text: a synthesis of recent research. Journal of Research in Science Teaching, 31(9), 895-911.

American Association for the Advancement of Science (AAAS). (1993). Benchmarks for scientific literacy: a Project 2061 report. New York: Oxford University Press.

Australian Bureau of Statistics (ABS). (2010). Schools, Australia (Cat. No. 4221.0). Canberra: ABS.

Australian Curriculum and Reporting Authority (ACARA). (2013). Australian Curriculum: Science F-10. Sydney: Commonwealth of Australia.

Ball, D. L., \& Cohen, D. K. (1996). Reform by the book: what is - or might be - the role of curriculum materials in teaching learning and instructional reform? Educational Researcher, 25(9), 6-8. 14.

Ball, D. L., \& Feiman-Nemser, S. (1988). Using textbooks and teachers' guides: A dilemma for beginning teachers and teacher educators. Curriculum Inquiry, 18, 401-423.

Banilower, E. R., Smith, P. S., Weiss, I. R., Malzahn, K. A., Campbell, K. M., \& Weis, A. M. (2013). Report of the 2012 national survey of science and mathematics education. Chapel Hill: Horizon Research, Inc.

Bazler, J. A., \& Simonis, D. A. (1991). Are high school chemistry textbooks gender fair? Journal of Research in Science Teaching, 28, 353-362.

Bennett, J., \& Hogarth, S. (2009). Would you want to talk to a scientist at a party? High school students' attitudes to school science and to science. International Journal of Science Education, 31(14), 1975-1998.

Carnine, L., \& Carnine, D. (2004). The interaction of reading skills and science content knowledge when teaching struggling secondary students. Reading \& Writing Quarterly, 20, 203-218.

Chall, J. S., \& Conard, S. S. (1991). Should textbooks challenge students? New York: Teachers College Press.

Chambliss, M. J., \& Calfee, R. C. (1998). Textbooks for learning: nurturing children's minds. Malden: WileyBlackwell.

Chiappetta, E. L., \& Koballa, T. (2002). Science instruction in the middle and secondary schools (5th ed.). Upper Saddle River: Merrill Prentice Hall.

Chiappetta, E. L., Sethna, G. H., \& Fillman, D. A. (1991). A quantitative analysis of high school chemistry textbooks for scientific literacy themes and expository learning aids. Journal of Research in Science Teaching, 28, 939-951.

Chiappetta, E. L., Sethna, G. H., \& Fillman, D. A. (1993). Do middle school life science textbooks provide a balance of scientific literacy themes? Journal of Research in Science Teaching, 30, 787-797.

Chiappetta, E. L., Ganesh, T. G., Lee, Y. H., \& Phillips, M. C. (2006). Examination of science textbook analysis research conducted on textbooks published over the past 100 years in the United States. San Francisco: Paper presented at the annual meeting of the National Association for Research in Science Teaching.

Cook, A., \& Tulip, D. (1992). The importance of selected textbook features to science teachers. Research in Science Education, 22, 91-100.

CST (Council for Science and Technology). (2000). Science teachers: A report on supporting and developing the profession of science teaching in primary and secondary schools. London: Her Majesty's Stationery Office.

Danaia, L., Fitzgerald, M., \& McKinnon, D. (2013). Students' perceptions of high school science: what has changed over the last decade? Research in Science Education, 43(4), 1501-1515.

Davis, E. A., \& Krajcik, J. S. (2005). Designing educative curriculum materials to promote teacher learning. Educational Researcher, 34(3), 3-14.

Dekkers, J., \& de Laeter, J. (2001). Enrolment trends in school science education in Australia. International Journal of Science Education, 23(5), 487-500.

DiGisi, L. L., \& Willett, J. B. (1995). What high school biology teachers say about their textbook use: a descriptive study. Journal of Research in Science Teaching, 32(2), 123-142.

Dunne, J., Mahdi, A. E., \& O'Reilly, J. (2013). Investigating the potential of Irish primary school textbooks in supporting inquiry-based science education (IBSE). International Journal of Science Education, 35(9), $1513-1532$.

Elgar, A. G. (2004). Science textbooks for lower secondary schools in Brunei: issues of gender equity. International Journal of Science Education, 26(7), 875-894.

Fang, Z. (2006). The language demands of science reading in middle school. International Journal of Science Education, 28(5), 491-520. 
Fang, Z., \& Wei, Y. (2010). Improving middle school students' science literacy through reading infusion. The Journal of Educational Research, 103, 262-273.

Fensham, P. J. (1997). School science and its problems with scientific literacy. In R. Levinson \& J. Thomas (Eds.), Science today: problem or crisis? London: Routledge.

Ford, D. J. (2004). Scaffolding preservice teachers' evaluation of children's science literature: attention to science-focused genres and use. Journal of Science Teacher Education, 15, 133-153.

Goodrum, D., Hackling, M., \& Rennie, L. (2001). The status and quality of teaching and learning of science in Australian schools. Canberra: Department of Education, Training and Youth Affairs.

Goodrum, D., Druhan, A., \& Abbs, J. (2012). The status and quality of year 11 and 12 science in Australian schools. Canberra: Report prepared for the Office of the Chief Scientist by the Australian Academy of Science.

Groves, F. H. (1995). Science vocabulary load of selected secondary science textbooks. School Science and Mathematics, 95(5), 231-235.

Guthrie, J. T., \& Wigfield, A. (2000). Engagement and motivation in reading. In M. L. Kamil, P. B. Mosenthal, P. D. Pearson, \& R. Barr (Eds.), Handbook of reading research (pp. 403-422). Mahwah: Erlbaum.

Hand, B., Alvermann, D., Gee, J., Guzzetti, B., Norris, S., Phillips, L., Prain, V., \& Yore, L. (2003). Message from the "Island Group": what is literacy in science literacy? Journal of Research in Science Teaching, 40, $607-615$.

Holliday, W. G. (1991). Helping students learn effectively from science text. In C. M. Santa \& D. E. Alvermann (Eds.), Science learning: processes and applications. Newark: International Reading Association.

Hubisz, J. (2003). Middle-school texts don't make the grade. Physics Today, 50-54.

Irez, S. (2009). Nature of science as depicted in Turkish biology textbooks. Science Education, 93(3), $422-447$.

Johnson, B. E., \& Zabrucky, K. M. (2011). Improving middle and high school students' comprehension of science texts. International Electronic Journal of Elementary Education, 4(1), 19-31.

Kahveci, A. (2010). Quantitative analysis of science and chemistry textbooks for indicators of reform: a complementary perspective. International Journal of Science Education, 32(11), 1495-1519.

Kenny, J., Lyons, T., \& Quinn, F. (2014). The continuing decline of science and mathematics enrolments in Australian high schools. Teaching Science, 60(2), 34-46.

Kesidou, S., \& Roseman, J. E. (2002). How well do middle school science programs measure up? Findings from project 2061's curriculum review. Journal of Research in Science Teaching, 39, 522-549.

Khine, M. S. (2013). Analysis of science textbooks for instructional effectiveness. In M. S. Khine (Ed.), Critical analysis of science textbooks: evaluating instructional effectiveness. Dordrecht: Springer.

King, C. J. H. (2010). An analysis of misconceptions in science textbooks: Earth Science in England and Wales. International Journal of Science Education, 32(5), 565-601.

Lee, V. R. (2010). Adaptations and continuities in the use and design of visual representations in US middle school science textbooks. International Journal of Science Education, 32(8), 1099-1126.

Lee, O., Eichinger, D., Anderson, C. W., Berkheimer, G. D., \& Blakeslee, T. D. (1993). Changing middle school students' conceptions of matter and molecules. Journal of Research in Science Teaching, 30, 249-270.

Lumpe, A. T., \& Beck, J. (1996). A profile of high school biology textbooks using scientific literacy recommendations. The American Biology Teacher, 58(3), 147-153.

Lyons, T., \& Quinn, F. (2010). Choosing Science: Understanding the declines in senior high school science enrolments. Armidale: National Centre of Science, ICT and Mathematics Education for Rural and Regional Australia, University of New England.

Maykut, P., \& Morehouse, R. (1994). Beginning qualitative research: a philosophic and practical guide. London: The Falmer Press.

MCEECDYA (Ministerial Council for Education, Early Childhood Development and Youth Affairs (2004). Demand and Supply of Primary and Secondary Teachers in Australia. http://www.mceecdya.edu.au/ mceecdya/publications, 11582 .

McKenzie, P., Kos, J., Walker, M., \& Hong, J. (2008). Staff in Australia's Schools 2007. Canberra: DEEWR.

Millar, R., \& Osborne, J. (1998). Beyond 2000: science education for the future. London: King's College.

Ninnes, P. (2000). Representations of indigenous knowledges in secondary school science textbooks in Australia and Canada. International Journal of Science Education, 22(6), 603-617.

Norris, S., \& Phillips, L. (2003). How literacy in its fundamental sense is central to scientific literacy. Science Education, 87, 224-240.

Office of the Chief Scientist. (2012). Health of Australian Science. Australian Government: Canberra.

Ogan-Bekiroglu, F. (2007). To what degree do the currently used physics textbooks meet the expectations? Journal of Science Teacher Education, 18, 599-628.

Organisation for Economic Co-operation and Development (OECD. (2013). PISA 2012 assessment and analytical framework: Mathematics, reading, science, problem solving and financial literacy. Paris: Author. 
Overman, M., Vermunt, J. D., Meijer, P. C., Bulte, A. M. W., \& Brekelmans, M. (2013). Textbook questions in context-based and traditional chemistry curricula analysed from a content perspective and a learning activities perspective. International Journal of Science Education, 35(17), 2954-2978.

Penney, K., Norris, S. P., Phillips, L. M., \& Clark, G. (2003). The anatomy of high school science textbooks. Canadian Journal of Science, Mathematics, and Technology Education, 3(4), 415-436.

Reddy, V. (2005). State of Mathematics and Science Education: Schools are not equal. Perspectives in Education, 23(3), 125-138.

Rennie, L. J., Goodrum, D., \& Hackling, M. Science teaching and learning in Australian schools: Results of a national study. Research in Science Education, 31, 455-498.

Roseman, J. E., Stern, L., \& Koppal, M. (2010). A method for analysing the coherence of high school biology textbooks. Journal of Research in Science Teaching, 47(1), 47-70.

Roth, W. M., Bowen, G. M., \& McGinn, M. K. (1999). Differences in graph-related practices between high school biology textbooks and scientific ecology journals. Journal of Research in Science Teaching, 36, 977-1019.

Schmidt, W., McKnight, C., \& Raizen, S. (1997). A splintered vision: an investigation of U.S. science and mathematics education. Lansing: Michigan State University.

Shamos, M. H. (1995). The myth of scientific literacy. New Brunswick: Rutgers University Press.

Shepardson, D. P., \& Pizzini, E. L. (1991). Questioning levels of junior high schools science textbooks and their implications for learning textual information. Science Education, 75(6), 673-682.

Slough, S. W., McTigue, E. M., Kim, S., \& Jennings, S. K. (2010). Science textbooks' use of graphical representation: a descriptive analysis of four sixth grade science texts. Reading Psychology, 31(3), 301-325.

Speering, W., \& Rennie, L. (1996). Students' perceptions about science: the impact of transition from primary to secondary school. Research in Science Education, 26, 283-298.

Stern, L., \& Roseman, J. E. (2004). Can middle-school science textbooks help students learn important ideas? Findings from project 2061's curriculum evaluation study: Life science. Journal of Research in Science Teaching, 41(6), 538-568.

Sue, V. M., \& Ritter, L. A. (2007). Conducting online surveys. Thousand Oaks: Sage.

Thomson, S., Hillman, K., Wernert, N., Schmid, M., Buckley, S., \& Munene, A. (2012). Highlights from TIMSS \& PIRLS 2011 from Australia's perspective. Melbourne: Australian Council for Educational Research (ACER).

Thomson, S., De Bortoli, L., \& Buckley, S. (2013). PISA in brief-highlights from the full Australian report: PISA 2012: how Australia measures up. Camberwell: Australian Council for Educational Research Ltd.

Tulip, D., \& Cook, A. (1993). Teacher and student usage of science textbooks. Research in Science Education, 23, 302-307.

Tytler, R. (2007). Re-imagining science education: engaging students in science for Australia's future. Camberwell: Australian Council for Educational Research.

Tytler, R., \& Osborne, J. (2012). Student attitudes and aspirations toward science. In B. J. Fraser, K. G. Tobin, \& C. J. McRobbie (Eds.), Second international handbook of science education (pp. 597-626). Dordrecht: Springer.

Tytler, R., Osborne, J., Williams, G., Tytler, K., \& Cripps Clark, J. (2008). Engagement in STEM across the primary-secondary school transition: opening up pathways. Canberra: DEEWR.

Unsworth, L. (1997). Some practicalities of a language-based theory of learning. Australian Journal of Language and Literacy, 20(1), 36-52.

Venville, G., Rennie, L., Hanbury, C., \& Longnecker, N. (2013). Scientists reflect on why they chose to study science. Research in Science Education, 43(6), 2207-2233.

Weis, A. M. (2013). 2012 National Survey of Science and Mathematics Education: status of middle school science. Chapel Hill: Horizon Research, Inc.

Wilkinson, J. (1999). A quantitative analysis of physics textbooks for scientific literacy themes. Research in Science Education, 29(3), 385-399. 